\title{
Calvarial Plasmacytoma Mimicking Meningioma as the Initial Presentation of Multiple Myeloma
}

\author{
Peter Morgenstern ${ }^{1}$, David Pisapia ${ }^{2}$, Rohan Ramakrishna ${ }^{3}$ \\ 1. Department of Neurological Surgery, New York-Presbyterian/Weill Cornell Medical Center 2. \\ Pathology, Weill Cornell Medical College 3. Department of Neurological Surgery, Weill Cornell Medical \\ College
}

$\square$ Corresponding author: Peter Morgenstern, pfmorgenstern@gmail.com Disclosures can be found in Additional Information at the end of the article

\section{Abstract}

Plasmacytoma of the calvarium is a well-described feature of multiple myeloma and in some cases has been reported as a solitary lesion. However, when associated with multiple myeloma these are typically identified after the initial diagnosis is made. This case is unusual in that the diagnosis of plasmacytoma was first suspected in a patient thought to have a meningioma on the day of surgery, when a magnetic resonance imaging (MRI) demonstrated spontaneous involution of the mass. Recognition of evolving changes in a calvarial or dural-based lesion should prompt the practitioner to consider alternative diagnoses other than meningioma prior to proceeding with surgical resection.

Categories: Neurosurgery, Oncology

Keywords: meningioma, plasmacytoma, multiple myeloma

\section{Introduction}

Plasma cell tumors are monoclonal proliferations of plasma cells that are most frequently observed in the context of their disseminated form: multiple myeloma. However, they may also occur as solitary plasmacytomas. Cranial plasmacytomas may arise from the skull, leptomeninges, or the brain parenchyma [1]. When observed without an existing diagnosis of multiple myeloma, these tumors can easily be mistaken for meningioma, metastasis, or lymphoma. Because of its high prevalence, meningioma is the most common misdiagnosis among patients with plasmacytoma [1]. We present a case in which a patient was thought to have a meningioma in the clinic and scheduled for surgical resection. At the time of surgery he was found to have a plasmacytoma and later diagnosed with multiple myeloma.

Received 02/02/2017 Review began 02/09/2017 Review ended 03/22/2017 Published 03/29/2017

\section{(C) Copyright 2017}

Morgenstern et al. This is an open access article distributed under the terms of the Creative Commons Attribution License CC-BY 3.0., which permits unrestricted use, distribution, and reproduction in any medium, provided the original author and source are credited.

\section{Case Presentation}

A 57-year-old man presented to the neurosurgical clinic complaining of headache after a workplace accident. He was found to have a right calvarial mass with compression of the right frontal lobe on head computed tomography (CT). A magnetic resonance imaging (MRI) of the brain demonstrated a contrast enhancing calvarial mass with features consistent with meningioma. In the context of the patient's unremarkable medical history, poorly controlled headaches and age, he was scheduled for elective resection. Aside from acetaminophen he took no additional medications for pain and was not started on any anti-inflammatory or steroid medications. 


\section{Cureus}

An MRI obtained three weeks later on the morning of surgery for use with intraoperative neuronavigation demonstrated a spontaneous reduction in the size of the lesion, raising the suspicion of an alternative diagnosis to meningioma (Figure 1). In discussion with the patient it was decided that, because of the size of the lesion and associated mass effect, it would be prudent to proceed with a minimally invasive biopsy followed by resection depending on the preliminary pathologic diagnosis. A frozen section at the time of surgery was non-diagnostic and described as a cellular neoplasm that could be consistent with an atypical meningioma given the sheet-like architecture. Lymphoma was not suspected given the cell size and amount of cytoplasm, and a plasmacytoid morphology was not appreciated, hampered in part by frozen section artifact. A gross total resection was performed. The patient recovered well and had an unremarkable perioperative course.
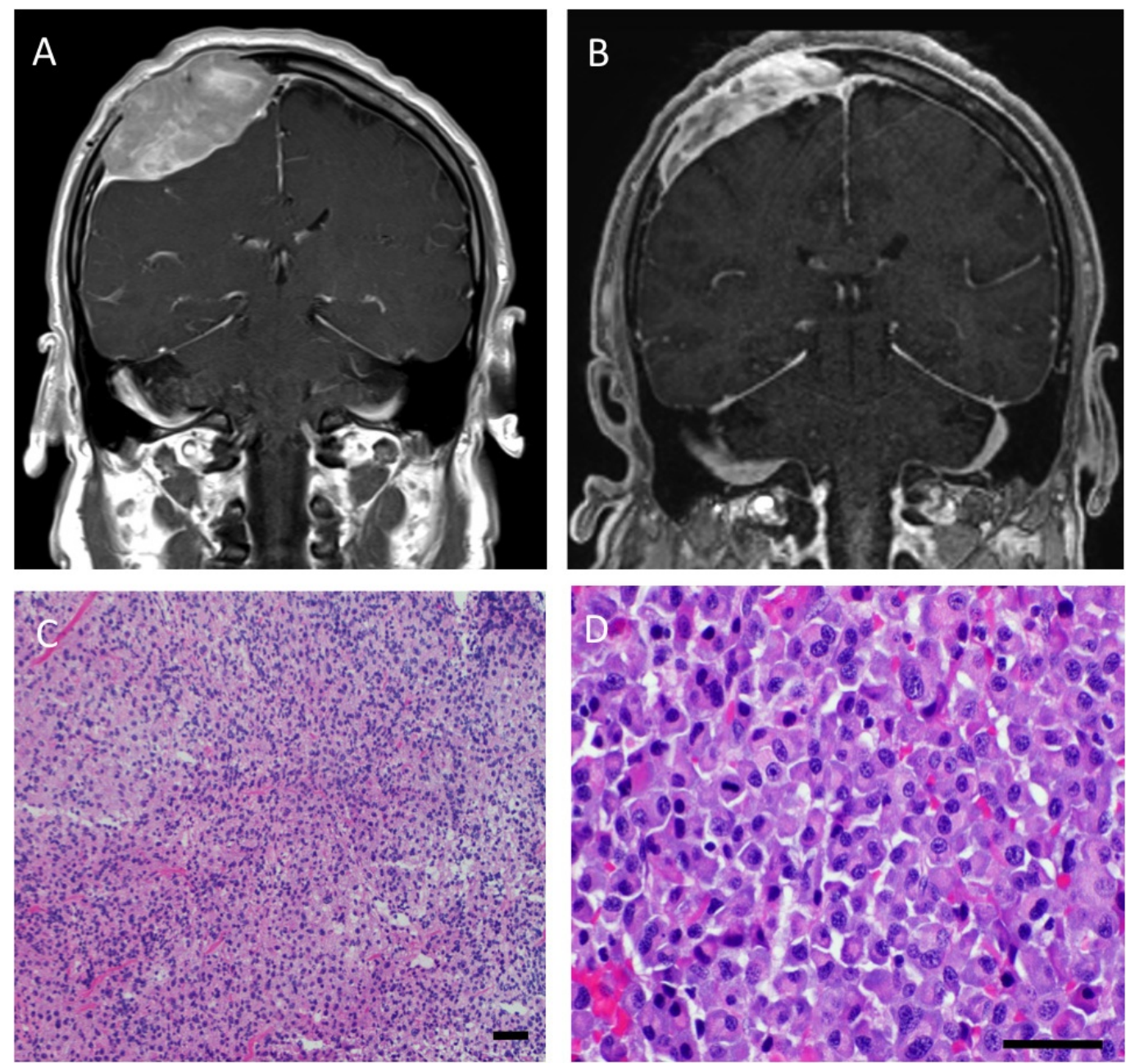

\section{FIGURE 1: Radiographic and histopathologic images}

Coronal gadolinium enhanced T1-weighted magnetic resonance imaging (MRI) at diagnosis (A) and on the day of surgery $(B)$ demonstrates reduction in the size of the right calvarial lesion. Hematoxylin and eosin staining of the frozen section (C) and permanent section (D, higher power) shows more distinct plasmacytoid morphology in the absence of frozen section artifact. Permanent section at high power reveals atypical plasma cells with mitotic figures, and multinucleation. Scale bars $=50 \mu \mathrm{m}$.

After permanent processing, the tumor was identified as a plasmacytoma $\left(\mathrm{CD} 138^{+}, \mathrm{CD} 56^{+}\right.$, Lambda $^{+}$, Kappa') with overall 30\% Ki67 positivity, eight percent in the $\mathrm{CD}^{-} 138^{+}$population. The 
patient underwent a systemic evaluation postoperatively, which revealed multiple lytic lesions in the humerus, glenoid process, and ribs. Serum protein electrophoresis (SPEP) was positive for immunoglobulin G (IgG)-Lambda, establishing the diagnosis of multiple myeloma. He initiated therapy in consultation with his hematologist/oncologist during the postoperative period. At nine months follow-up, he was doing well with a Karnofsky performance status (KPS) of 90 and continuing maintenance chemotherapy.

\section{Discussion}

Dural-based plasmacytoma mimicking meningioma has been described previously, typically involving the leptomeninges and skull concurrently [1-5]. Solitary cranial plasmacytoma occurs rarely and usually occurs as a manifestation of multiple myeloma as in this case $[2-4,6]$. However, spontaneous involution of a plasmacytoma without therapeutic intervention has not been previously reported.

Because of their rarity, the literature on the management of cranial plasmacytoma is limited. One important facet of this discussion is the role of surgical resection. Consensus at this time suggests that for solitary plasmacytoma the management is gross total resection with adjuvant radiation therapy [1-2,7-8]. However, the appropriate management of plasmacytomas associated with multiple myeloma is less definitive. Most authors suggest chemotherapy with radiation as the first line for these lesions, even when there is a mass effect, because of their exquisite sensitivity to this approach [9-10]. Surgical resection is typically reserved for those refractory to therapy or unable to receive radiation due to proximity to sensitive structures such as the optic chiasm. A histopathologic study by Schwartz, et al. examined cell adhesion molecules and plasmacytoma location and a possible correlation to later development of multiple myeloma. It was suggested that cranial base location is more predictive of a subsequent diagnosis of multiple myeloma. Furthermore, it was noted that extramedullary dural-based lesions were unlikely to be associated with multiple myeloma and therefore should be resected [2]. Our case is an exception to this conclusion in that a convexity dural-based lesion represented a plasmacytoma that was later found to be a presentation of multiple myeloma.

In the case described here, the differential diagnosis at the time of intraoperative frozen section included meningioma and solitary plasmacytoma, and gross total resection was performed. However, given the subsequent diagnosis of multiple myeloma in the first several days postoperatively, we would recommend a preoperative workup for multiple myeloma prior to making treatment decisions when plasmacytoma enters the differential diagnosis.

\section{Conclusions}

This case is unusual in that a tumor initially thought to be meningioma reduced in size substantially prior to surgery in the absence of steroid or other medical therapy. Identification of this finding preoperatively altered the initial operative plan, prompting a small preliminary biopsy prior to proceeding with resection. Recognition of such evolution of a dural-based or calvarial mass should prompt further evaluation prior to proceeding with surgery in order to identify occult cases of multiple myeloma.

\section{Additional Information}

\section{Disclosures}

Human subjects: Consent was obtained by all participants in this study. Informed consent obtained. Conflicts of interest: In compliance with the ICMJE uniform disclosure form, all authors declare the following: Payment/services info: All authors have declared that no financial support was received from any organization for the submitted work. Financial 
relationships: All authors have declared that they have no financial relationships at present or within the previous three years with any organizations that might have an interest in the submitted work. Other relationships: All authors have declared that there are no other relationships or activities that could appear to have influenced the submitted work.

\section{References}

1. Azarpira N, Noshadi P, Pakbaz S, et al.: Dural plasmacytoma mimicking meningioma . Turk Neurosurg. 2014, 24:403-405. 10.5137/1019-5149.JTN.5735-12.1

2. Schwartz TH, Rhiew R, Isaacson SR, et al.: Association between intracranial plasmacytoma and multiple myeloma: clinicopathological outcome study. Neurosurgery. 2001, 49:10391045. 10.1097/00006123-200111000-00002

3. Sahin F, Saydam G, Ertan Y, et al.: Dural plasmacytoma mimicking meningioma in a patient with multiple myeloma. J Clin Neurosci. 2006, 13:259-261. 10.1016/j.jocn.2005.03.033

4. Hasturk AE, Basmaci M, Erten F, et al.: Solitary dural plasmacytoma mimicking meningioma and invading calvarium. J Craniofac Surg. 2013, 24:175-177. 10.1097/SCS.0b013e31827c85ba

5. Meyer JR, Roychowdhury S, Cybulski G, et al.: Solitary intramedullary plasmacytoma of the skull base mimicking aggressive meningioma. Skull Base Surg. 1997, 7:101-105. 10.1055/s2008-1058616

6. Wilberger AC, Prayson RA: Intracranial involvement by plasma cell neoplasms . Am J Clin Pathol. 2016, 146:156-162. 10.1093/ajcp/aqw058

7. Bindal AK, Bindal RK, van Loveren $\mathrm{H}$, et al.: Management of intracranial plasmacytoma. J Neurosurg. 1995, 83:218-221. 10.3171/jns.1995.83.2.0218

8. Frerich JM, Patel C, Dhiantravan V, et al.: Impaired diagnosis and successful management of a rare intra-axial central nervous system plasmacytoma in a patient with multiple myeloma. Clin Neurol Neurosurg. 2014, 117:112-115. 10.1016/j.clineuro.2013.11.017

9. Jordan DR, Drouin J, Berry G, et al.: Intracranial plasmacytoma associated with multiple myeloma. Can J Ophthalmol. 1984, 19:275-278.

10. Webb M, Barrett C, Barrett S, et al.: Cranial plasmacytoma: a case series and review of the literature. Indian J Hematol Blood Transfus. 2013, 29:43-47. 10.1007/s12288-011-0126-7 